\title{
Evaluation of participants' feedback after a simulation-based training in neonatal resuscitation using a realistic delivery room*
}

\author{
Alejandro Avila-Alvarez $^{1 \#}$, Iria Gonzalez-Rivera ${ }^{2}$, Jose L. Fernandez-Trisac ${ }^{1}$, \\ Maria I. Taboada-Perianes ${ }^{1}$, Bruno Rodriguez-Gonzalez ${ }^{3}$, Alberto Centeno-Cortes ${ }^{4}$, \\ Maria Diaz-Gomez ${ }^{5}$, Teresa Rei-Serra ${ }^{2}$, Rita Jacome-Feijoo ${ }^{2}$ \\ ${ }^{1}$ Unidade de Neonatoloxía, Servizo de Pediatría, Complexo Hospitalario Universitario A Coruña, A Coruña, Spain \\ ${ }^{2}$ Unidade de Cuidados Intensivos Pediátricos, Servizo de Pediatría, Complexo Hospitalario Universitario A Coruña, A Coruña, Spain \\ ${ }^{3}$ Servizo de Urxencias, Hospital Arquitecto Marcide, Ferrol, Spain \\ ${ }^{4}$ Centro Tecnolóxico de Formación, Complexo Hospitalario Universitario de A Coruña, A Coruña, Spain \\ ${ }^{5}$ Servizo de Xinecoloxía e Obstetricia, Complexo Hospitalario Universitario de A Coruña, A Coruña, Spain \\ Email: "
}

Received 8 July 2012; revised 15 August 2012; accepted 13 September 2012

\begin{abstract}
BACKGROUND: Low-frequency and high-risk situations, such as neonatal resuscitation, are the ideal targets for simulation-based learning. The aim of this paper is to present the structure of our internal neonatal resuscitation training program, using a realistic, simulated delivery room, and to present the participants' opinions about teamwork, emotional stress, and their subjective ability to face a resuscitation. METHODS: We administered a training course to 24 doctors and midwives. One of the simulation classrooms was modified to appear similar to a real delivery room. Four scenarios were conducted using a previously designed checklist of primary and secondary goals. Upon completion, all students participated in a debriefing session with the help of a video review. RESULTS: Students rated the achievement of their previously defined goals on a scale of 1 to 5 . Grouping together the percentages of the highest ratings (Categories 4 and 5), $83.4 \%(20 / 24)$ of the students considered the course useful for acquiring clinical skills. For $87.5 \%(21 / 24)$ of the students, the scenarios simulated real clinical situations, the room properly simulated a real delivery room, and the course improved the students' ability to work in a team. For $66.6 \%(16 / 24)$ of the students, the course improved their stress in confronting neonatal resuscitation. Initially, only $33.3 \%(8 / 24)$ of the students

\footnotetext{
"Competing interest: We declare no competing interests: All the authors of the manuscript have no propietary, financial, professional or other relationships with any people, company or organisation that could inappropriately influence the material discussed in the manuscript.

"Corresponding author.
}

considered themselves very capable or fully able to cope with a resuscitation. After the course, that percentage rose to $62.5 \%(15 / 24)$. CONCLUSIONS: The incorporation of simulation-based learning into neonatal resuscitation teaching programs, using realistic scenarios, is useful and offers the possibility of acquiring technical skills, but it also allows for the improvement of teamwork and the adoption of different roles and positive attitudes towards emotional stress.

Keywords: Neonatal Resuscitation; Simulation; Training

\section{INTRODUCTION}

"Javier is a second-year resident in paediatrics. At 2:00 in the morning, he is called to the delivery room. It is a 39 weeks' gestation, without prior obstetrical complications, but with a worrisome foetal cardiac recording. The newborn is born hypotonic, pale, and apnoeic. Javier, who has the neonatal resuscitation algorithm memorised, is prepared to receive him, but he decides to find the telephone to call the neonatologist quickly while the midwife tries to stimulate the infant. Javier is very nervous; the 5 min it takes for the consultant to arrive seem like an eternity. He has not even managed to select a mask of the correct size when the neonatologist takes charge of the situation. The baby is intubated and ventilated, the heart rate is recovering, and the colour is improving. Javier remains immobile in the middle of the delivery room."

Fortunately, the need for neonatal resuscitation is an infrequent occurrence. It is estimated that $10 \%$ of new- 
borns will require some type of intervention in the delivery room, but less than $1 \%$ will require advanced resuscitation manoeuvres [1]. It is a commonly accepted practice that, in the face of life-threatening situations such as the resuscitation of a newborn, the most expert person takes charge and performs the pertinent manoeuvres to minimise the risks to the patient. In this scenario, how can we guarantee adequate training in neonatal resuscitation? Moreover, how can we accomplish this training while guaranteeing the safety of the patient?

Medical simulation has experienced a great expansion in recent years, and these developments have been incorporated effectively into various training programs. Previously, its utility had been proven in military environments, aeronautics, and the management of accidents or natural disasters, but its application in medicine has clashed with the concept of traditional teaching based on the transmission of theory and learning by "imitation and repetition" on the patient. With initial misgivings having been overcome, simulation in medicine has offered results similar to those obtained in other disciplines [2-5].

Low-frequency, high-risk situations, such as neonatal resuscitation, are the ideal targets for learning through simulation. The current evidence for the utility of simulation has led the American Heart Association (AHA) and the American Academy of Pediatrics (AAP) to recommend in their latest guidelines that simulation techniques be adopted in the design of their training program for neonatal resuscitation: the Neonatal Resuscitation Program (NRP) [6].

The objective of the present study was to make known the structure of our internal training program for neonatal resuscitation, using a simulated delivery room, as well as to present the opinions of the participants and to reflect on the possible applications of simulation in neonata$\log$.

\section{MATERIALS AND METHODS}

\subsection{Material and Human Resources}

The course took place in the "Technological Training Centre”, part of the A Coruña University Hospital, in Spain. One of the simulation rooms was modified specifically to have the appearance of a real delivery room, as presented in Figure 1. Students had available to them all the necessary materials for attending to a newborn, according to the latest recommendations, including an oxygen-air blender, a $\mathrm{T}$ resuscitator (Neopuff ${ }^{\circledR}$ ), and polyethylene bags.

The Prompt Birthing Simulator ${ }^{\circledR}$ obstetrical simulation

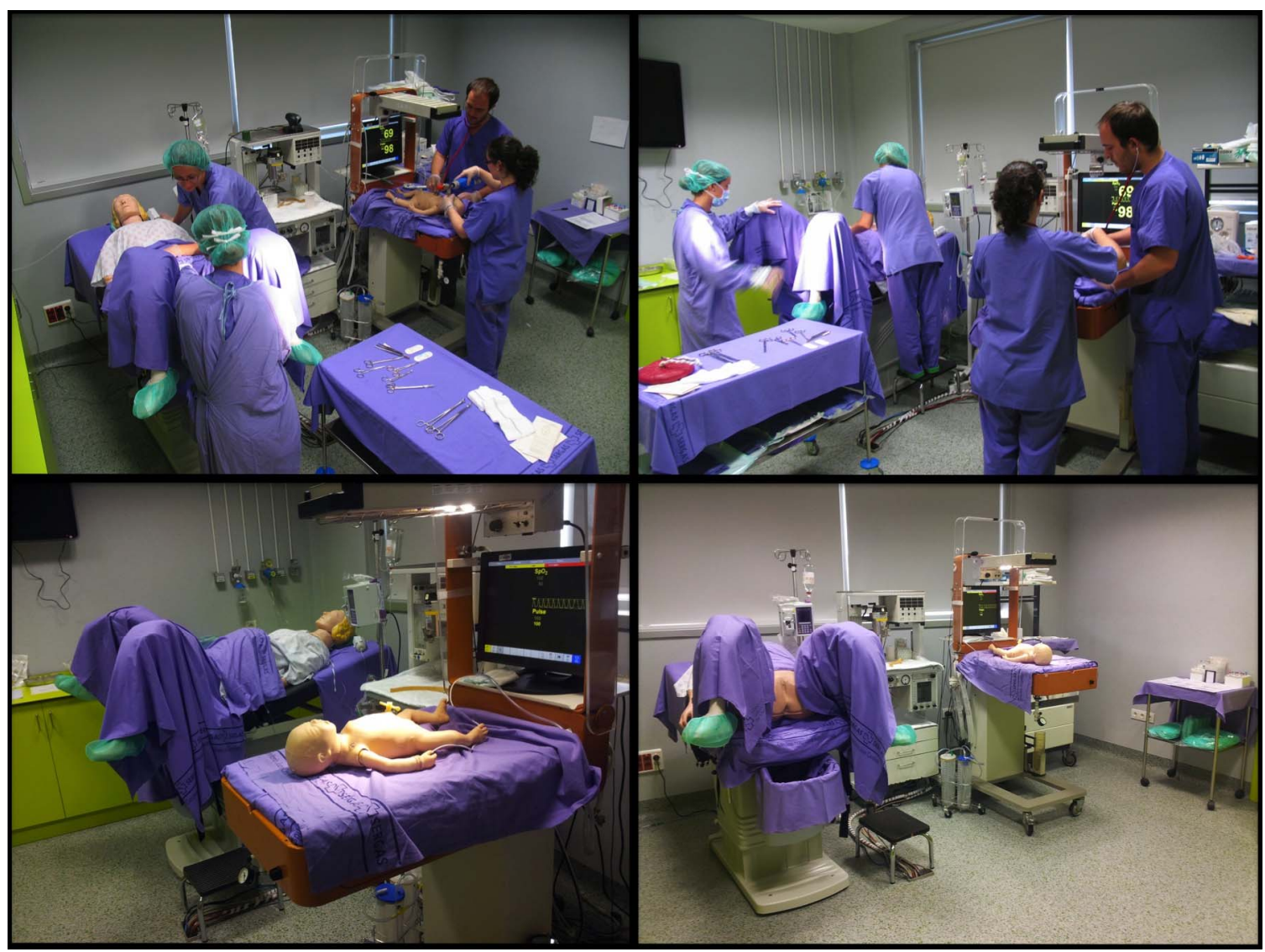

Figure 1. Simulation room specifically modified to give the appearance of a real delivery room. 
mannequin (Limbs and Things, United Kingdom) was used and it was attended by an obstetrician from the hospital staff who had previously rehearsed the role to be performed. As a simulator for the newborn, the SimNewB ${ }^{\circledR}$ (Laerdal Medical Corporation, Norway) was used.

A recording system with four high-definition cameras and an ambient microphone located in the resuscitation warmer were used.

The course instructors were three neonatologists, a paediatric intensivist, and a general practitioner, all of whom had previous experience in simulation courses and three of whom were certified resuscitation instructors.

\subsection{Course Design}

The course took place on June 20-21 2011, in two groups of 12 students per day with a total of 24 students. The course was accredited by the "Spanish National Health System's Continuing Training Commission”. All students signed an informed consent to be recorded during the simulation. No student received economic or any other type of compensation, other than his or her own learning, for participating.

The training began with a non-contact phase, which consisted of the study of theoretical training materials specifically designed for the course and based on the latest international recommendations for neonatal resuscitation [1].

The contact phase began with a short theoretical review of the new resuscitation algorithm and with the completion of a game for the various groups that consisted of putting together a 50-piece puzzle. This game was used as an icebreaker and as an example to illustrate the importance of teamwork, the establishment of roles, and defining a strategy.

Next, simulation cases were examined. Four scenarios were defined with the following titles that the students did not know:

- Anticipation and preparation: first steps;

- Ventilation with positive pressure;

- Advanced resuscitation: medication; and

- Resuscitation of premature infants.

Each case was resolved by a group of three students consisting of the following:

- A midwife;

- A second- or third-year resident; and

- A fourth-year resident or a general paediatrician.

The rest of the students in the course watched the cases directly, using a screen installed in the adjacent classroom. For evaluation and later discussion, each scenario had a checklist that contained two or three primary objectives and a wider series of secondary objectives. Table 1 shows an example of a list of objectives. The cases lasted between 10 and 20 minutes. At the end, all students, both those who had completed the simulation and those who had watched from the outside, reunited in a single classroom and watched, discussed, and analysed the case as a debriefing exercise (Figure 2). The role of the instructor was, as much as possible, to be simply a moderator or facilitator, guaranteeing that the primary objectives were discussed, whereas the secondary objectives were discussed only if brought up spontaneously by the students.

At the end of the day, the students were asked to complete an anonymous opinion survey.

\section{RESULTS}

Table 2 shows the baseline characteristics of the group of students.

After the course, the students scored different items on a scale from 1 (complete disagreement) to 5 (complete agreement). In Table 3 , the mean, median, and mode of these scores are shown.

The survey indicated that $83.4 \%(20 / 24)$ of the respondents agreed or completely agreed (Categories 4 and 5) that the course allowed them to acquire useful abilities for clinical practice and for teamwork. Furthermore, $87.5 \%(21 / 24)$ of the students agreed or completely agreed that the scenarios simulated real clinical situations and that the room adequately simulated a real delivery room. The debriefing afterward appeared useful or very useful to all of the students (24/24).

Table 1. Example of a checklist for one of the scenarios (Scenario 2: ventilation with positive pressure).

\section{PRIMARY OBJECTIVES}

$$
\begin{aligned}
& \text { Assign roles, identify a leader } \\
& \text { Identify the need for ventilation } \\
& \text { Ventilation technique }
\end{aligned}
$$

\section{SECONDARY OBJECTIVES}

Ask about risk factors (obstetric history)

Open airway (position airway, secretions) Start timer

Place under a heat source

Dry, change wet diapers

Stimulation manoeuvres

Place pulse oximeter

Start ventilation with $21 \% \mathrm{FiO}_{2}$

Limit inspiratory pressure (PIP)

Prepare intubation supplies

Control heart rate, respiration, and $\mathrm{O}_{2}$ saturation after $30 \mathrm{~s}$

Place nasogastric tube 
Table 2. Baseline characteristics of students in the course.

Second- or third-year resident, $33.3 \%$

(8)

What position do you hold at the hospital?

Fourth-year resident, 16.6\% (4)

Paediatrician, $16.6 \%(4)$

Midwife, 33.3\% (8)

Every day, 25\% (6)

How often do you attend to newborns in the delivery room?

Every week, 50\% (12)

Every month, 20.8\% (5)

Less than once per month, $4.2 \%$ (1)

More than a year ago, $12.5 \%$ (3)

When did you last participate in a neonatal resuscitation?

Within the past year, 12.5\% (3)

In the past 6 months, $4.2 \%$ (1)

In the past month, $70.8 \%$ (17)

$\begin{array}{cc}\begin{array}{c}\text { Have you taken any courses in } \\ \text { neonatal resuscitation? }\end{array} & \text { Yes, 75\% (18) } \\ \begin{array}{c}\text { Do you consider yourself } \\ \text { capable of attending a neonatal } \\ \text { resuscitation? }\end{array} & \text { No, 25\% (6) } \\ \begin{array}{c}\text { Do you consider yourself } \\ \text { capable of directing/leading a } \\ \text { neonatal resuscitation? }\end{array} & \text { No, 12.5\% (3) } \\ & \text { Yes, 20.8\% (5) } \\ & \text { No, 79.2\% (19) }\end{array}$

Table 3. Measurements of central tendency (mean, median, and mode) of students' scores, with 1 indicating complete disagreement and 5 indicating complete agreement.

\begin{tabular}{|c|c|c|c|}
\hline Question & Mean & Median & Mode \\
\hline $\begin{array}{l}\text { Have we covered the objectives proposed } \\
\text { by the organisation? }\end{array}$ & 4.46 & 5 & 5 \\
\hline $\begin{array}{l}\text { My objectives have been covered at the } \\
\text { beginning of the course. }\end{array}$ & 4.33 & 4.5 & 5 \\
\hline $\begin{array}{l}\text { I have acquired knowledge or abilities that } \\
\text { will serve me in my clinical practice. }\end{array}$ & 4.38 & 5 & 5 \\
\hline $\begin{array}{l}\text { I believe that the course improved my } \\
\text { ability to work in a team. }\end{array}$ & 4.29 & 4 & 4 \\
\hline $\begin{array}{l}\text { I believe that the course improved my stress } \\
\text { at confronting a resuscitation. }\end{array}$ & 3.96 & 4 & 4 \\
\hline $\begin{array}{l}\text { I believe that the course improved my } \\
\text { theoretical knowledge of resuscitation. }\end{array}$ & 4.25 & 4 & 5 \\
\hline $\begin{array}{l}\text { I believe that the course improved my } \\
\text { technical abilities in resuscitation. }\end{array}$ & 4.17 & 4 & 4 \\
\hline $\begin{array}{l}\text { The scenarios simulated real clinical } \\
\text { situations. }\end{array}$ & 4.46 & 5 & 5 \\
\hline The room simulated a real delivery room. & 4.35 & 4 & 4 \\
\hline The scenarios fit the proposed objectives. & 4.42 & 5 & 5 \\
\hline $\begin{array}{c}\text { The debriefing afterward seemed useful to } \\
\text { me. }\end{array}$ & 4.58 & 5 & 5 \\
\hline
\end{tabular}

After completing the course, the students scored their subjective capacity to face a resuscitation from 1 (completely incapable) to 5 (completely capable). Initially, only $33.3 \%$ of the students rated themselves with a 4 or 5 . After the course, this percentage rose to $62.5 \%$ (15/24).
Figure 3 schematises the answers to this question.

\section{DISCUSSION}

Neonatal resuscitation is an infrequent situation, but it requires a rapid and regulated intervention aimed at recovering cardiopulmonary circulation. In this situation, the establishment of roles and teamwork is of paramount importance, as is the skill of each of the participants in performing the necessary techniques. It is obvious that all medical training should involve, in some way, training with real patients, but this training should be undertaken in such a way as to guarantee the principle of non-malfeasance with minimal repercussions for the prognosis of the patient $[7,8]$.

The objective of this study was not to introduce the general theoretical benefits of simulation in training, as they can be found easily in the literature $[9,10]$. Briefly, we can highlight that mannequins or robots offer, on the one hand, the possibility of unlimited repetition of a particular technique and, on the other hand, the possibility of training in teamwork and the division of labour. Although it is more difficult to evaluate and related to the idiosyncrasies of the student, the simulation of stress situations can also decrease the anxiety with which we confront these situations in real life.

Learning can be defined as the systematic acquisition of knowledge, skills, and attitudes [11]. Traditional teaching of medicine, in particular of resuscitation, has centred on the first two, with an important theory load and practice with more or less real mannequins. However, the experience in other fields has demonstrated the necessity for also training students in "attitude" and teamwork. If everyone can understand why a group of good soccer players should train together even being individually the best players, then there is no reason to leave teamwork out of resuscitation training. In a very vivid and successful manner, this process has been represented with the question "How to turn a team of experts into an expert medical team [11]”?

Learning through simulation involves three aspects: first, a situation as realistic as possible should bring with it the student's sense of responsibility (scenario); second, the performance of the student should provoke direct changes in the situation of the patient or robot (simulator); and third, an analysis afterward of what happened (debriefing) should take place.

Numerous studies in recent years have demonstrated that training through simulation and debriefing is an effective tool for improving performance in real clinical situations [2-5]. Other studies, in contrast, have not found differences between traditional methods and simulationbased methods [12,13]. Evaluating the efficacy of simulation as a teaching technique is difficult, and findings have been extremely variable across different studies. 


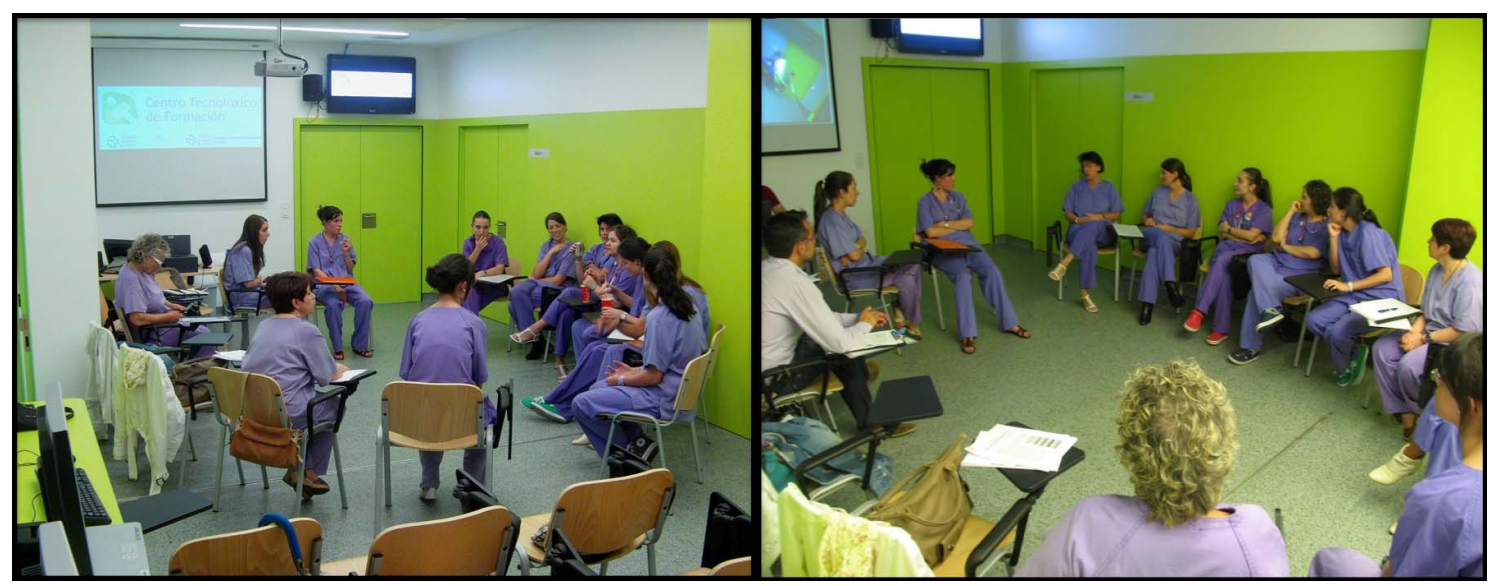

Figure 2. Debriefing session.

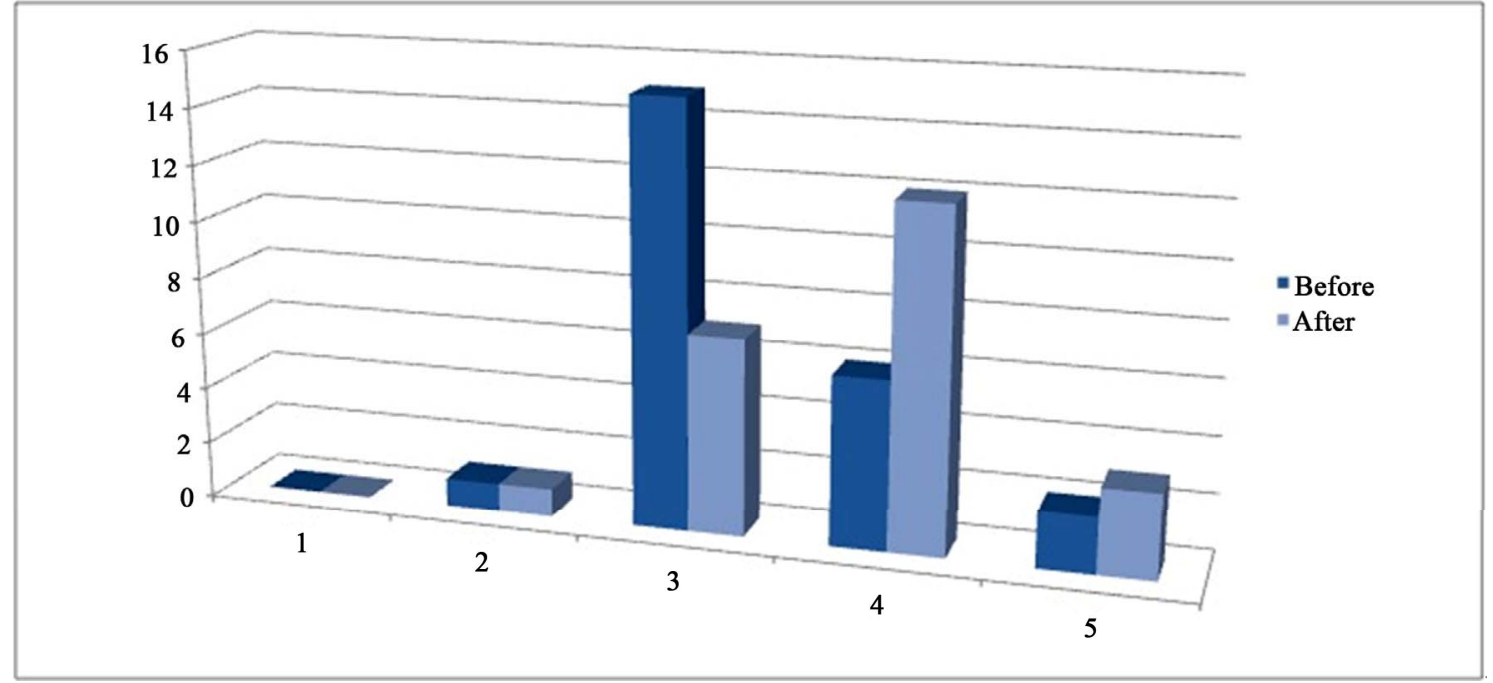

Figure 3. Bar graph that represents the students' subjective perception of their ability to confront a resuscitation before and after the course, with 1 indicating being completely incapable and 5 indicating being completely capable.

The intent to evaluate the effects of simulation on technical ability and on results with real patients is methodologically complicated, particularly in situations such as neonatal resuscitation. By evaluating the feedback of the participants we can determine whether training with simulation changes the attitude of the student towards confronting the taught situation. Thus, one has in mind their opinion and their perceptions of teamwork, leadership, communications, and behavioural skills [9,14]. The basis of this evaluation is the question, "What do you think about $\cdots$ ?” In our course, the opinions of the students about their subjective capacity building and about the stress with which they approached neonatal resuscitation were very favourable, as were their opinions about teamwork and the acquisition of theoretical and technical abilities.

Simulation has been demonstrated to be a useful tool during the period of residency [15-17], but its utility is not limited to those years of training or to inexpert pro- fessionals; rather, it could also serve in re-training programs for situations for which low frequency impedes their practice with assiduity and, thus, the maintenance of previously acquired abilities.

In neonatology, the use of simulation for training medical students, residents, nurses, anaesthetists, neonatologists, and gynaecologists has been reported [13, 18-20]. The current evidence has led the International Liaison Committee on Resuscitation (ILCOR), in their recent 2010 recommendations, to promote the use of simulation and debriefing techniques in neonatal resuscitation training. Likewise, the AHA and the AAP recommended, in their latest guidelines, to the NRP the adoption of simulation and debriefing techniques in the design of the NRP's training program [6]. In addition, the European Resuscitation Council considers simulation "An essential part of resuscitation training [21]." At the time of completion of our course, the latest edition of the NRP textbook had not yet been released; however, the 
principal changes could be previewed by reading the AAP and AHA guidelines, and many articles anticipated the inclusion of simulation as an educational tool [22]. Recently, we have witnessed the local adaptation of our country to these new international changes, and simulation and debriefing techniques are mentioned with their application to neonatal resuscitation training [23].

Administering our first injections into an orange or sewing pigs' ears can be considered, in a very broad sense, simulation techniques, with the objective of approximating the best possible likeness to reality. In resuscitation training, from the first "Resusci Anne" through actual interactive mannequins, the effort has always been aimed at conferring a more "real" appearance to the taught situation [20,24-26]. Currently, the incorporation of new audio-visual technologies, as well as the involvement of industry, has permitted the attainment of more realistic scenarios. In neonatology, Halamek, et al. previously reported good results in neonatal resuscitation training by imitating a real delivery room in their scenarios $[18,20]$. In the same manner, we attempted with our scenario to imitate in the most reliable way possible a delivery room, paying attention to small details, such as the presence of a staff gynaecologist or the adaptation of an obstetric care simulator. The opinions of the students in our course regarding the realism of the room and the scenarios supported our efforts in that respect.

To offer, as in our case, the latest generation mannequins or simulators is useful and provides a great deal of versatility, but it also involves a significant economic investment and requires a rather tedious learning curve. In our opinion, the latest market models, although advantageous, are dispensable to the creation of realistic scenarios or to the adaptation of simulation techniques to medical training.

Work with lists of objectives or checklists has been described previously in other courses $[27,28]$. The division of these lists into primary and secondary objectives guarantees that the most important elements of resuscitation are not overlooked while at the same time avoiding excessive interventionism on the part of the monitor in debriefing.

\section{CONCLUSIONS}

The incorporation of simulation into neonatal resuscitation training, using a realistic delivery room, can serve not only for training in technical abilities and improving theoretical knowledge but also for improving teamwork, alleviating emotional stress, and improving behavioural skills.

Medical simulation is an important tool that can be used to guarantee adequate training in neonatal resuscitation while at the same time guaranteeing the safety of the patient.

\section{REFERENCES}

[1] Perlman, J.M., Wyllie, J., Kattwinkel, J., Atkins, D.L., Chameides, L., Goldsmith, J.P., et al. (2010) On behalf of the neonatal resuscitation chapter collaborators. Part 11: Neonatal resuscitation: 2010 International consensus on cardiopulmonary resuscitation and emergency cardiovascular Care sciencie with treatment recommendations. Circulation, 122, S516-S538. doi:10.1161/CIRCULATIONAHA.110.971127

[2] Knudson, M.M., Khaw, L., Bullard, M.K., Dicker, R., Cohen, M.J., Staudenmayer, K., et al. (2008) Trauma training in simulation: Translating skills from SIM time to real time. The Journal of Trauma, 64, 255-263. doi:10.1097/TA.0b013e31816275b0

[3] Wayne, D.B., Didwania, A., Feinglass, J., Fudala, M.J., Barsuk, J.H. and McGaghie, W.C. (2008) Simulationbased education improves quality of care during cardiac arrest team responses at an academic teaching hospital: A case-control study. Chest, 133, 56-61. doi:10.1378/chest.07-0131

[4] Brett-Fleeger, M.B., Vinvi, R.J., Weiner, D.L., Harris, S.K., Shih, M.C. and Kleinman, M.E. (2008) A simulatorbased tool that asseses pediatric resident resuscitation competency. Pediatrics, 121, 597-603. doi:10.1542/peds.2005-1259

[5] Schwid, H., Rooke, G., Ross, B. and Sivarajan, M. (1999) Use of a compoturized advanced cardiac life support simulator improves retention of advanced cardiac life support guidelines better than a textbook review. Critical Care Medicine, 27, 821-824. doi:10.1097/00003246-199904000-00045

[6] Kattwinkel, J., Perlman, J.M., Aziz, K., Colby, C., Fairchild, K., Gallagher, J., et al. (2010) Part 15: Neonatal resuscitation: 2010 American heart association guidelines for cardiopulmonary resuscitation and emergency cardiovascular care. Circulation, 122, S909-S919. doi:10.1161/CIRCULATIONAHA.110.971119

[7] Ziv, A., Wolpe, P.R., Small, S.D. and Glick, S. (2003) Simulation-based medical education: An ethical imperative. Academic Medicine, 78, 783-788. doi:10.1097/00001888-200308000-00006

[8] Lynoe, N., Sandlund, M., Westberg, K. and Duchek, M. (1998) Informed consent in clinical training: Patient experiences and motives for participating. Medical Education, 32, 465-471. doi:10.1046/j.1365-2923.1998.00237.x

[9] Perkins, G.D. (2007) Simulation in resuscitation training. Resuscitation, 73, 202-211. doi:10.1016/j.resuscitation.2007.01.005

[10] Delasobera, B.E., Goodwin, T.L., Strehlow, M., et al. (2010) Evaluating the efficacy of simulators and multimedia for refreshing ACLS skills in India. Resuscitation, 81, $217-$ 223. doi:10.1016/j.resuscitation.2009.10.013

[11] Burke, C.S., Salas, E., Wilson-Donelly, K., Priest, H., et al. (2004) How to turn a team of experts into an expert medical team: Guidance from the aviation and military 
communities. Quality \& Safety in Health Care, 13, 96104. doi:10.1136/qshc.2004.009829

[12] Shapiro, M.J., Morey, J.C., Small, S.D., Langford, V., Kaylor, C.J., Jagminas, L., et al. (2004) Simulation based teamwork training for emergency department staff: Does it improve clinical team perfomance when added to an existing didactic teamwork curriculum. Quality \& Safety in Health Care, 13, 417-421. doi:10.1136/qshc.2003.005447

[13] Cavaleiro, A.P., Guimaraes, H. and Calheiros, F.L. (2009) Training neonatal skills with simulators. Acta Paediatrica, 98, 636-639. doi:10.1111/j.1651-2227.2008.01176.x

[14] Halamek, L.P., Kaegi, D.M., Gaba, D.M., Sowb, Y.A., Smith, B.C., Smith, B.E., et al. (2000) Time for a new paradigm in pediatric medical education: Teaching neonatal resuscitation in a simulated delivery room environment. Pediatrics, 106, 45-48. doi:10.1542/peds.106.4.e45

[15] Southgate, W.M. and Annibale, D.J. (2010) Simulation training in graduate medical education. A means of traversing a changed and changing landscape. Advances in Neonatal Care, 5, 261-268. doi:10.1097/ANC.0b013e3181f08d38

[16] Falucco, E.M., Hanson, M.D. and Glowinski, A.L. (2010) Teaching pediatric residents to assess adolescent suicide risk with a standarized patient module. Pediatrics, 125, 953-959. doi:10.1542/peds.2009-2135

[17] Nadel, F.M., Lavelle, J.M., Fein, J.A., Giardino, A.P., Decker, J.M. and Durbin, D.R. (2000) Assessing pediatric senior residents training in resuscitation: Fund of knowledge, technical skills, and perception of confidence. Pediatric Emergency Care, 16, 73-76. doi:10.1097/00006565-200004000-00001

[18] Campbell, D.M., Barozzino, T., Farrugia, M. and Sgro, M. (2009) High-fidelity simulation in neonatal resuscitation. Paediatrics \& Child Health, 14, 19-23.

[19] Rovamo, L., Mattila, M.M., Andersson, S. and Rosenberg, P. (2011) Assessment of newborn resuscitation skills of physicians with a simulator manikin. Archives of Disease in Childhood, 96, 383-389.
[20] Halamek, L.P. (2008) The simulated delivery-room environment as the future modality for acquiring and maintaining skills in fatal and neonatal resuscitation. Seminars in Fetal and Neonatal Medicine, 13, 448-453. doi:10.1016/j.siny.2008.04.015

[21] Soar, J., Monsieurs, K.G., Balance, J.H.W., et al. (2010) European resuscitation council guidelines for resuscitation 2010 section 9. Principles of education in resuscitation. Resuscitation, 81, 1434-1444. doi:10.1016/j.resuscitation.2010.08.014

[22] Kattwinkel, J. and Perlman, J. (2010) The neonatal resuscitation program: The evidence evaluation process and anticipating edition 6. NeoReviews, 11, e673-e680.

[23] Iriondo, M., Szydl, E., Vento, M., Burón, E., Salguero, E., Aguayo, J., et al. (2010) Changes in the international recommendations on neonatal resuscitation 2010: Comments. An Pediatr (Barc), in press.

[24] Brilli, R.J., Spevezt, A., Branson, R.D., Campbell, G.M., Cohen, H., Dasta, J.F., et al. (2001) Critical care delivery in the intensive care unit: Defining clinical roles and the best practice model. Critical Care Medicine, 29, 207-219. doi:10.1097/00003246-200110000-00026

[25] Sawyer, T., Hara, K., Thompson, M.W., Chan, D.S. and Berg, B. (2009) Modification of the laerdal simbaby to include an integrated umbilical cannulation task trainer. Simulation in Healthcare, 4, 174-178. doi:10.1097/SIH.0b013e31817bcaeb

[26] Murphy, A.A. and Halamek, L.P. (2005) Simulationbased training in neonatal resuscitation. NeoReviews, 6, e489-e492. doi:10.1542/neo.6-11-e489

[27] van der Heide, P.A., van Toledo-Eppinga, L. and van der Heide, M. (2006) Assessment of neonatal resuscitation skills: A reliable and valid scoring system. Resuscitation, 71, 212-221. doi:10.1016/j.resuscitation.2006.04.009

[28] Lockyer, J., Singhal, N., Fidler, H., Weiner, G., Aziz, K. and Curran, V. (2006) The development of a perfomance checklist to assess neonatal resuscitation megacode skill. Pediatrics, 118, 1739-1744. 